\title{
LÓGICA DEÔNTICA, DILEMAS MORAIS E CONTRADIÇÃO
}

\author{
uma introdução à discussão sobre a formalização dos dilemas morais na lógica deôntica
}

\author{
DEONTIC LOGIC, MORAL DILEMMAS AND CONTRADICTION \\ an introduction to the discussion on formalization of moral dilemmas in deontic logic
}

Eric Bitencourt de Santana ${ }^{l}$

(bitencourteric@hotmail.com)

\begin{abstract}
RESUMO
Com o desenvolvimento das lógicas não clássicas, novas maneiras de representar um discurso e analisá-lo surgiram. A lógica deôntica foi fundada com o intuito de analisar o discurso ético. Os dilemas morais são um caso especial na ética, pois a discussão de sua existência ou não afeta a visão filosófica sobre o modo que a ética normativa deve lidar com seus princípios e se estes devem permitir o surgimento dos dilemas morais (MARCUS, 1980, p. 121). Neste trabalho,pesquisou-se sobre como a discussão dos dilemas morais pode interferir nas diferentes fundamentações dos sistemas de lógica deôntica. A análise inicia-se a partir de uma apresentação breve da lógica deôntica e logo depois inclui as posições favoráveis e contrárias aos dilemas morais (LEMMON, 1962, p. 139 e CONEE, 1982, p. 87). Verifica-se também se há um comprometimento entre a justificativa da existência dos dilemas morais e os postulados em um sistema deôntico. Conclui-se que há um tipo de comprometimento entre a defesa dos dilemas morais e os pressupostos lógicos assumidos nos sistemas deônticos.
\end{abstract}

Palavras-chave: Ética. Lógica. Dilemas morais. Lógica deôntica.

\begin{abstract}
With the development of non-classical logics, new ways of representing a discourse and analyzing it have emerged. Deontic logic was founded with the purpose of analyzing the ethical discourse. Moral dilemmas are a special case in ethics as the discussion of their existence or not affects the philosophical view on how normative ethics should deal with its principles and whether they should permit the appearence of moral dilemas (MARCUS, 1980, p. 121). In this work we investigated if the discussion of moral dilemmas can interfere in the different foundations of existing deontic logic systems. The analysis begins with a brief presentation of deontic logic and then includes the favorable and contrary positions to the moral dilemas (LEMMON, 1962, p. 139 and CONEE, 1982, p. 87). Lastly, it was verified if there is a compromise between the justification of the existence of the moral dilemmas and the axioms assumed in a deontic system. It is concluded that there is some kind of a compromise between the defense of the moral dilemmas and the logical presuppositions assumed in any deontic systems.
\end{abstract}

\footnotetext{
${ }^{1}$ Graduando em Filosofia pela Universidade Federal de Santa Catarina (UFSC).

Lattes: http://lattes.cnpq.br/2996729012032558.

ORCID: https://orcid.org/0000-0003-1838-5570.
} 
Keywords: Ethics. Logic. Moral dilemmas. Deontic logic.

\section{INTRODUÇÃO}

Com o desenvolvimento de diferentes sistemas de lógica, como as lógicas modais aléticas, novas maneiras de representar um universo de discurso e analisá-lo sistematicamente surgiram. É também conhecido que a linguagem formal da lógica clássica é limitada, apesar do seu poder representativo. A formalização de noções de possibilidade e necessidade em proposições como, por exemplo, “É possível que chova amanhã” não é algo captável pela linguagem artificial usual da lógica clássica. Logo após o surgimento da lógica modal alética, a lógica deôntica também começou a ser estudada. Do grego deon, o termo deôntico se refere ao dever. Por analogia, a lógica deôntica trataria então de representar nossas noções intuitivas de dever em um sistema lógico.

Nesse sentido, ela pode se apresentar tanto como uma ferramenta de análise do discurso normativo quanto um método para discutir as consequências lógicas de regras e normas dentro do campo da ética. Neste trabalho, entende-se como "discurso normativo" todo aquele discurso composto por sentenças as quais denotam uma noção modal de obrigação, permissão ou proibição. Por exemplo: as proposições "É permitido fumar" e "É proibido cometer homicídio" pertencem ao discurso normativo. Se a lógica deôntica for utilizada como uma ferramenta para analisar nosso discurso normativo, caberá a ela corresponder, dentro de um devido sistema formal, às nossas noções modais normativas presentes no discurso da linguagem comum. Quando dizemos que a lógica deôntica analisa o discurso normativo, querse dizer que, dado um sistema lógico deôntico em uma linguagem formal, espera-se que ele seja capaz de representar o discurso normativo natural de modo geral. Em outras palavras, espera-se que podemos formalizar as proposições usadas no discurso ético e analisar as implicações lógicas disso. Argumentos envolvendo proposições normativas poderiam, em tese, ser analisados por um sistema deôntico.

Entretanto, um problema muito peculiar surge na literatura quando falamos dos dilemas morais. Entendemos um dilema moral como uma situação $\mathrm{S}$ onde duas ações $\mathrm{A}$ e $\mathrm{B}$ são obrigatórias, mas ou só A ou só B podem ser realizadas. Dito de outro modo, um agente P qualquer é obrigado a seguir um curso de ação A e obrigado a seguir um curso de ação B, mas não pode seguir ambos os cursos de ação juntos. Se os dilemas morais estão no discurso normativo, é natural indagar se eles poderiam ser representados 
dentro de um sistema deôntico ou não. Esse será o assunto central dentro deste artigo. Nosso objetivo neste trabalho é introduzir o leitor à discussão sobre os dilemas morais e a formalização deles na lógica deôntica, apresentando algumas das implicações éticas e lógicas dessa discussão.

Os dilemas morais entendidos da maneira acima desafiam os estudiosos da área de Ética e Lógica. O principal problema a ser exposto aqui será o da formalização dos dilemas morais na lógica deôntica clássica. Existem três alternativas para solucionar o problema da formalização dos dilemas morais na lógica deôntica (GOBLE, 2005, p. 465). Ademais, também apresentaremos se há algum tipo de relação entre a existência ou não dos dilemas morais e o modo que eles podem ser formalizados em um determinado sistema lógico. Para isso, será necessário também compreender como a literatura lida com a ontologia dos dilemas morais.

Em um primeiro momento, apresentaremos a lógica deôntica clássica utilizada na literatura. Outros sistemas lógicos deônticos surgiram com o intuito de evitar o problema (inerente à lógica deôntica clássica) relacionado com os dilemas morais. O cálculo paraconsistente deôntico monádico² é um deles (DA COSTA; CARNIELLI, 1986, p. 300). Há também o cálculo bimodal (deôntico-alético) (AMARAL, 2012, p. 62). Essas são algumas das várias tentativas de formalização dos dilemas morais na lógica deôntica dentro da literatura. Apesar de citarmos aqui, não entraremos em detalhes nesses sistemas ou nas suas tentativas e motivações para resolver esses problemas.

Em segundo lugar, apresentaremos a discussão dos dilemas morais a partir das posições de E.J Lemmon e Ruth Marcus que sustentam a existência deles. Earl Conee, por outro lado, apresenta objeções às razões expostas por ambos.

Em terceiro e último lugar concluímos este trabalho apresentando se o comprometimento com a existência de dilemas morais acarreta em consequências lógicas, apresentando futuros trabalhos a serem explorados nessa área.

\section{DESENVOLVIMENTO}

2 Uma lógica deôntica monádica é aquela cujo operador de obrigação $O$ liga-se somente a uma proposição. Daí o nome monádica. Em lógicas deônticas diádicas, por exemplo, o operador $\mathrm{O}$ liga-se a duas proposições, denotando uma noção de comprometimento ou restituição em um sentido amplo (CRUZ, 2005, p. 77). 
Para delimitarmos o problema a ser discutido, dividiremos este trabalho em três partes. $\mathrm{Na}$ primeira parte, apresentaremos um panorama da literatura sobre lógica deôntica e na segunda, a discussão dos dilemas morais. Na última parte, argumentaremos se é o caso de que as concepções sobre os dilemas morais influenciam ou não o modo deles serem formalizados na lógica deôntica.

\subsection{Lógica deôntica}

Uma breve descrição sobre o desenvolvimento da lógica deôntica padrão é necessária para esclarecer em que ponto a discussão contemporânea sobre os dilemas morais se encontra. Chamamos de sistemas deônticos precedentes todos aqueles sistemas de lógica deôntica que precedem a lógica deôntica padrão. Os sistemas deônticos precedentes apresentados brevemente neste artigo serão dois: a lógica Deontik de Ernst Mally e a lógica deôntica de G. H. Von Wright.

Sabe-se que o primeiro filósofo a desenvolver uma teoria formal de conceitos normativos foi Ernst Mally em 1926 (HILPINEN, 1981, p. 1). Apesar de ter formado um sistema completamente diferente do que se conhece hoje como lógica deôntica, os primeiros passos para o desenvolvimento contemporâneo vieram da teoria de Mally.

A teoria axiomática lidava com variáveis proposicionais que representavam estados de coisas e com a noção de que essas proposições eram possíveis ou deveriam ser o caso. Por exemplo: ! $p$ estaria dizendo que "p é obrigatório". A variável proposicional 'p', neste caso, se refere a estados de coisas, como por exemplo, "O livro está sobre a mesa". Além disso, Mally adotava uma variável proposicional $u$ como o "incondicionalmente obrigatório". Um estudo mais aprofundado da lógica de Mally pode ser visto em (LOKHORST, 1999, p. 273-274). A partir de diversas contestações e questões postas sobre o trabalho de Mally, surge então a lógica deôntica de Von Wright.

\subsubsection{O sistema de lógica deôntica de Von Wright}

Anos depois, George Henrik Von Wright divulga um pequeno artigo chamado Deontic Logic. Nele, Von Wright sustenta uma lógica do dever que, segundo ele, funciona de modo análogo às noções de possibilidade e necessidade. $\mathrm{O}$ operador de obrigatoriedade age semelhantemente ao de necessidade, e o de permissibilidade 
semelhante ao de possibilidade. Dentro do sistema de Von Wright considera-se também que as variáveis são atos e não proposições por si só (VON WRIGHT, 1951, p. 5). Elas seriam atos como "matar" ou "enganar". Tomando o operador de obrigatoriedade como 'O', e a variável 'p' como 'enganar', Op seria 'É obrigatório enganar'. Para Von Wright, não é possível ter uma iteração de obrigatoriedade. Isso exclui a formação de sentenças como OOp (lê-se 'é obrigatório que é obrigatório que $p$ ') dentro de seu sistema. Tais tipos de sentenças compostas pela iteração de operadores deônticos não seriam válidas em seu sistema.

Os axiomas que G.H. Von Wright assume no seu artigo são:

$$
\begin{aligned}
& (\mathrm{W} 1)(\mathrm{Op} \leftrightarrow \sim \mathrm{P} \sim \mathrm{p}) \\
& (\mathrm{W} 2)(\mathrm{Pp} \vee \sim \mathrm{Pp}) \\
& (\mathrm{W} 3) \mathrm{P}(\mathrm{p} \vee \mathrm{q}) \leftrightarrow(\mathrm{Pp} \vee \mathrm{Pq})
\end{aligned}
$$

Para fins de objetividade, consideraremos a leitura usual dos conectivos lógicos $(\mathrm{V}, \leftrightarrow$, $\rightarrow, \sim)$ e das formações de fórmulas como a da lógica proposicional clássica, com o acréscimo dos operadores $\mathrm{P}$ (permitido) como primitivo O (obrigatório) definido por (W1). Cada um dos postulados parece ter um significado correspondente à nossa linguagem moral. (W1) define o operador de obrigatoriedade tomando o operador ' $\mathrm{P}$ ' como primitivo. A proposição " $\mathrm{p}$ é permitido" pode ser denotada como Pp. (W2) é o chamado de "princípio da permissão" e denota que para qualquer ato $p$, ou $p$ é permitido ou $\sim p$ é permitido. E, por fim, (W3) é o chamado "princípio da distribuição deôntica". Ele postula que $p$ ou $q$ são permitidos se e somente se $p$ é permitido ou $q$ é permitido. Além disso, von Wright considera um princípio chamado de princípio da contingência deôntica que postula o seguinte: "Um ato tautológico não é necessariamente obrigatório, e um ato contraditório não é necessariamente proibido" (VON WRIGHT, 1951, p. 10).

Portanto, as fórmulas $\mathrm{O}(\mathrm{p} \vee \sim \mathrm{p})$ e $\sim \mathrm{P}(\mathrm{p} \& \sim \mathrm{p})$ não seriam válidas neste sistema. Por fim, ele admite as regras de inferência da lógica clássica e acrescenta mais uma: dada uma proposição $(\alpha \leftrightarrow \beta)$ pode-se inferir $(\mathrm{P} \alpha \leftrightarrow \mathrm{P} \beta)$. Por preceder uma semântica de mundos possíveis que seria mais bem desenvolvida futuramente, o sistema teve de ser reinterpretado (HILPINEN, 1981, p. 13).

\subsubsection{Lógica deôntica padrão}


O sistema mais discutido e analisado na literatura atualmente é o sistema de lógica deôntica padrão. Esse sistema é baseado no sistema modal alético D. ${ }^{3}$ Para a apresentação do sistema de lógica deôntica padrão, será necessário definir uma linguagem e, em seguida, quais fórmulas são fórmulas bem-formadas dentro dessa linguagem artificial. Por fim, quais são os axiomas e teoremas.

Uma linguagem $\mathscr{L}$ é composta por:

(1) Um conjunto infinito enumerável de variáveis proposicionais $\left\{p, q, \ldots, p_{1}, p_{2}\right.$, $\left.\ldots, p_{n}\right\}$ que representa as proposições da linguagem;

(2) Um conjunto contendo todos os operadores lógicos: $\{\sim, \&, \mathrm{~V}, \rightarrow, \leftrightarrow, \mathrm{O}, \mathrm{P}\}$;

(3) Parênteses para a pontuação da linguagem '(' e ')'.

Definição 1. As fórmulas da linguagem $\mathscr{L}$ são:

(1) Todas as variáveis proposicionais são fórmulas;

(2) Se $\alpha$ e $\beta$ são fórmulas, então ‘ $\sim \alpha$ ', '( $\alpha \& \beta)$ ', '( $\alpha \vee \beta)$ ', ‘( $\alpha \rightarrow \beta)$ ', ‘( $\alpha \leftrightarrow \beta)$ ', $\mathrm{O} \beta$ e P $\beta$ também são fórmulas;

(3) Essas são as únicas fórmulas.

A interpretação dos conectivos é a usual ${ }^{4}$, com o acréscimo do operador O e P. Se $p$ é

uma proposição, então $O p$ lê-se como 'É obrigatório que $p$ '. A leitura do operador de permissibilidade é feita analogamente. Com a linguagem e as fórmulas bem-formadas definidas, resta-nos apresentar os axiomas do sistema. Os seguintes axiomas e regras são assumidos na lógica deôntica padrão:

(D1) Todos os axiomas do cálculo proposicional clássico.

(D2) $(\mathrm{Pp} \leftrightarrow \sim \mathrm{O} \sim \mathrm{p})$;

(D3) $\mathrm{O}(\mathrm{p} \rightarrow \mathrm{q}) \rightarrow(\mathrm{Op} \rightarrow \mathrm{Oq})$;

(D4) $\mathrm{Op} \rightarrow \mathrm{Pp}$;

(RD1) Se temos $\vdash$ p e $\vdash$ p $\rightarrow$ q, então $\vdash$ q ${ }^{5}$

$(\mathrm{RD} 2) \vdash \mathrm{p} / \vdash \mathrm{Op}$.

A discussão filosófica sobre os axiomas da logica deôntica clássica surge a partir dos paradoxos que esse sistema acaba por acarretar. Alguns teoremas como o paradoxo de Prior (paradoxo do bom samaritano), de Chisholm (paradoxo do imperativo contrário-ao-dever) e o

3 Os sistemas aléticos diferenciam-se pelas suas relações de acessibilidade da semântica (ou dos axiomas assumidos no sistema). Na semântica do sistema $\mathrm{D}$, por exemplo, a relação de acessibilidade dos mundos possíveis é serial (AMARAL, 2012, p. 31).

4 Sejam ' $p$ ' e ' $q$ ' proposições. ' $\sim p$ ' lê-se como 'não é o caso que $p$ ', '(p \& q)' lê-se como ' $p$ e $q$ ',

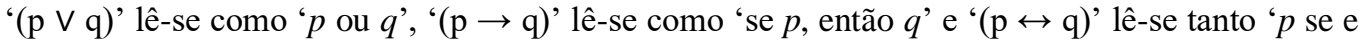
somente se $q$ ' como ' $p$ é equivalente a $q$ '.

5 Lê-se " $-\mathrm{p} \rightarrow \mathrm{q}$ " como "a fórmula 'se $\mathrm{p}$, então q' é um teorema". 
de Ross (paradoxo do comprometimento) motivam a busca de alterações no sistema deôntico padrão (SILVA, 2017, p. 676 e HILPINEN, 1981, p. 21). Apesar de serem chamados de paradoxos, esses teoremas não são inconsistências em um sentido técnico no sistema, com exceção do paradoxo de Chisholm, mas assim são chamados por fornecerem interpretações contraintuitivas quando lidos sob a linguagem natural.

O paradoxo de Ross, por exemplo, decorre de que, se é obrigatório que $p$, então é obrigatório $p$ ou $q$. $\mathrm{Na}$ linguagem $\mathscr{L}$, isso pode ser escrito como '(Op $\rightarrow \mathrm{O}(\mathrm{p} \vee \mathrm{q}))$ '. Ao fornecermos uma interpretação às proposições ' $p$ ' e ' $q$ ' como, respectivamente, 'enviar uma carta' e 'queimar uma carta', lê-se como "se é obrigatório enviar uma carta, então é obrigatório enviá-la ou queimá-la". Como corolário desse teorema, dada qualquer obrigação relacionada a uma ação, isso implica na obrigatoriedade da disjunção entre essa ação e outra ação qualquer. Em outras palavras, uma obrigação implica na facultatividade entre duas ações. Ela é contraintuitiva nesse sentido.

Já o paradoxo de Prior apresenta uma versão semelhante ao paradoxo anterior apresentado: ( $\neg \mathrm{Pp} \rightarrow \neg \mathrm{P}(\mathrm{p} \& \mathrm{q})$ ). Dada a mesma interpretação para $p$ e $q$ oferecida acima, lêse tal teorema do seguinte modo "se não é permitido enviar uma carta, então não é permitido enviá-la e queimá-la”. De modo análogo ao paradoxo de Ross, esse paradoxo nos diz que para uma proibição, há também a proibição de uma conjunção de ações.

Uma discussão sobre a axiomática da lógica deôntica clássica merece menção aqui. Os Para Amaral, os axiomas (D2) e (D4) parecem estar de acordo com nossa intuição e o axioma (D3) parece não fazer sentido (AMARAL, 2012, p. 36). A interpretação do consequente desse axioma parece não encaixar com nossa nossas intuições deônticas (AMARAL, 2012, p. 39). Todavia, parece haver um equívoco na análise proposta por ela. A análise é a seguinte: consideremos a leitura do antecedente ' $\mathrm{O}(\mathrm{p} \rightarrow \mathrm{q})$ ' de uma instância de (D3) como 'é obrigatório que, se João engravidou Maria, então ele se case com ela'. Em seguida, Amaral assume que a leitura do consequente '(Op $\rightarrow \mathrm{Oq})$ ' do axioma não faria sentido, pois 'Op' significaria que 'é obrigatório engravidar Maria'. Contudo, discordamos de tal conclusão. Para interpretarmos corretamente o axioma, é essencial analisar a fórmula, e não somente seus componentes isoladamente. A interpretação de Amaral sobre o antecedente do axioma está correta, mas não podemos dizer o mesmo do consequente. A leitura do consequente do axioma (D3) que faria maior sentido é a seguinte: 'se é obrigatório que João engravide Maria, então é obrigatório que ele se case com ela'. 
O que há, na verdade, é tão somente uma noção de comprometimento com as obrigações que esse axioma intuitivamente nos oferece. Por ser um axioma que está presente nas lógicas aléticas D, que utilizam a noção de possibilidade e necessidade, falar de (D3) pode causar certa contraintuitivididade. Mas a noção de comprometimento fornecida por (D3) não é tão longínqua da intuição que temos sobre o comprometimento que está presente no discurso ético natural. Se 'é obrigatório que, se João engravide Maria, então se case com ela', parece razoável admitir que se for o caso (supondo que haja uma obrigação moral entre João e Maria de que eles tenham um filho, ou de algum modo comprometeram-se a tal ato), seria o suficiente para concluir que João estaria comprometido, isto é, é obrigado, a se casar com Maria.

Outra análise proposta é a da regra (RD2) que também poderia ser descartada. Ela impõe que dado um teorema, ele também deve ser obrigatório. Por exemplo: ' $O(p \vee \sim p)$ '. Segundo essa regra, essa fórmula seria um teorema dentro do sistema deôntico padrão e, portanto, verdadeira em todos os mundos possíveis, o que pareceria não fazer sentido, já que podem existir mundos possíveis que não contenham obrigações (AMARAL, 2012, p. 38).

Devido aos questionamentos filosóficos sobre a axiomática do sistema padrão deôntico, novos sistemas surgiram na tentativa de abarcar melhor o discurso normativo, como os que foram mencionados no início deste artigo. Todavia, devemos mantermo-nos na lógica deôntica clássica durante este trabalho e voltar-nos-emos para o teorema ' (Op \& O p)', o qual chamaremos de (DM). As análises seguintes mostrarão qual o papel deste teorema dentro da discussão dos dilemas morais e suas formalizações.

\subsection{Dilemas morais}

O termo 'dilema moral' na ética pode ter vários significados. Neste trabalho devemos especificar sobre qual tipo de dilema moral pretendemos analisar. Os dilemas morais poderiam ser considerados apenas como situações onde há conflitos morais. Entretanto, aqui falamos de dilemas morais nos referindo àquelas situações onde um agente deve fazer $\mathrm{A}$, deve fazer B, mas não pode fazer ambas as ações. Desse modo, excluímos a possibilidade de lidarmos com dilemas morais como o dilema do bonde (trolley problem) (FOOT, 1967, p. 2).

Há de se fazer uma distinção importante entre esses tipos de dilemas morais e os que serão assunto deste artigo. Nos dilemas do tipo trolley, os quais não serão abordados aqui, o agente não sabe qual ação é a correta. A questão pertinente 
nessas situações é: "é correto fazer A ou fazer B?"6. Por outro lado, os dilemas morais no sentido definido no início deste parágrafo denotam que o agente sabe o que é correto a se fazer, ou seja, ele sabe que deve fazer tanto A quanto B, mas essas duas ações se excluem de algum modo e não se sabe qual curso de ação deve ser escolhido.

O artigo Moral Dilemmas, retrata cinco tipos de situações morais que costumam ser tratadas pela ética (LEMMON, 1962, p. 139). São duas que nos interessam e se referem aos dilemas morais tratados aqui. O primeiro dilema tipo é o dilema de Platão e o segundo é o dilema de Sartre (MARCUS, 1980, p. 121). Cada um deles tem suas peculiaridades, mas o ponto central é o mesmo: em uma formalização na lógica deôntica padrão, uma contradição ocorreria.

\begin{abstract}
"Um amigo dá sua arma a mim afirmando que ele estará de volta à noite, e eu prometo devolvê-la quando ele voltar. Ele volta louco, exige sua arma e anuncia que vai atirar em sua esposa porque ela foi infiel. Devo devolver a arma, desde que prometi agir dessa maneira - neste caso, tenho uma obrigação. E, no entanto, não devo devolvê-la, pois agir desse modo me tornaria indiretamente responsável por um assassinato, e meus princípios morais que adoto consideram isso errado. Estou em um dilema moral, aparentemente resolvido por não devolver a arma." (LEMMON, 1962 p. 148, tradução nossa).
\end{abstract}

Lemmon está correto em dizer que esse dilema moral em específico é um dilema entre uma obrigação e um princípio moral ${ }^{7}$. Para ele, seria uma obrigação devolver a arma e cumprir a promessa, mas o correto a se fazer é manter a arma longe do homem louco.

O dilema de Sartre, de maneira muito simplificada, é o seguinte: um aluno jovem de Sartre é obrigado a ficar com sua mãe e ao mesmo tempo ele deve a partir do dever de um

6 Em particular, o dilema do bonde nos propõe um conflito moral em que um bonde, em seu trajeto usual, atingiria cinco pessoas que estão no caminho dele. Um agente, contudo, pode evitar essas mortes por meio do acionamento de uma alavanca. Esse acionamento fará com que o bonde troque seu trajeto, onde uma pessoa só será atingida pelo veículo. A pergunta pertinente é: seria correto que o agente acionasse a alavanca?

7 A distinção entre obrigação, dever e princípios morais é essencial para compreender a posição de Lemmon. Para o filósofo, existem três fontes de obrigação: duty, obligation e os moral principles. 'Duty', traduzida como 'dever', é todo dever relacionado a algum cargo ou posição. Por exemplo: um dos deveres de um pai é o de cuidar do seu filho. 'Obligation', traduzida como 'obrigação', é um comprometimento por meio de ações anteriores. Se, por exemplo, prometemos cumprir uma promessa, cumprir a promessa se torna uma obrigação. Os princípios morais, por fim, definem aquilo que é correto de acordo com um código moral adotado (LEMMON, p. 140-142, 1962). 
cidadão, ir às Forças Francesas Livres e à guerra. Neste caso, temos um dilema entre uma obrigação e um dever.

Aparentemente, a distinção entre duty, obligation e moral principle feita por Lemmon traz dilemas morais como consequência principal. A solução para os dilemas poderia ser alcançada por dois métodos: poder-se-ia criar uma hierarquia entre esses três tipos de obrigação ou manter uma ordem complexa deles (LEMMON, 1962, p. 151). Poderíamos dizer que os deveres são mais importantes que as obrigações, dissolvendo o dilema moral pelo primeiro método. $\mathrm{O}$ segundo método seria hierarquizar os deveres categorizados no seguinte sentido: definir que 'a obrigação como filho deve sobrepor os deveres de alguém como cidadão’. A partir disso, os dois dilemas acima seriam resolvidos.

Contudo, sabendo que o estabelecimento dessas diferentes fontes de obrigação fornece fundamentação a alguns dilemas morais, esse pano de fundo teórico é questionado e comentaremos quais são as objeções (CONEE, 1982, p. 88).

"Eu gostaria de argumentar que um homem deve fazer algo se é seu dever fazer isso. Semelhantemente, ele deve fazer algo se ele está sob a obrigação de fazer isso e deve fazer se de acordo com a perspectiva de um princípio moral que ele adota, ele deveria fazer isso." (LEMMON, 1962, p. 148, tradução nossa)

Para Lemmon, portanto, que um agente deve moralmente cometer um ato $x$ se pelo menos uma das seguintes condições está satisfeita (LEMMON, 1962, p. 140):

(i) é dever dele fazer $x$

(ii) está sob a obrigação de fazer $x$.

(iii) deve fazer $x$ na perspectiva de um princípio moral que ele adota;

À primeira vista, essa noção de agir moral é bastante intuitiva. O seguinte contraexemplo parece derrubar essas pressuposições do agir moral: suponha um carrasco em um campo de concentração. Ele certamente deve assassinar suas vítimas, pois se compromete de algum modo com essa obrigação, seja adotando um conjunto de princípios morais ou assinando um documento/contrato que o compromete com essa obrigação (CONEE, 1982, p. 88). Mas não parece razoável admitir que tal comprometimento contratual implique em um agir moral como diz a condição (i) e nem em uma obrigação moral, conforme (ii). A condição (iii) também não acarretaria em um agir correto, já que um carrasco adotaria um princípio moral que impõe que o assassinato de pessoas é um agir moral. Se for verdade que os dilemas morais se sustentam somente do fato de que há uma distinção dos três 
tipos deveres apresentados anteriormente, eles cairiam por terra com esse contraexemplo.

Outra defensora dos dilemas morais é Ruth Marcus. Uma das situações utilizadas como exemplo para ilustrar dilemas morais está nas situações como a dos gêmeos que estão em perigo. Pressuponha a seguinte situação: dois gêmeos estão se afogando em um lago, e cada um deles deve ser salvo, mas ambos não podem ser salvos (MARCUS, 1980, p. 125). Se for verdade que os dois cursos de ação, salvar o gêmeo A (ato A) e o gêmeo B (ato B), são moralmente equivalentes, então o dilema moral está estabelecido (CONEE, 1962, p. 92).

Dados dois atos x e y, eles serão moralmente equivalentes se e somente se o valor moral de cada curso de ação não se sobreponha por certo princípio, lei ou norma. Nesse caso, o ato A e B são moralmente equivalentes, ou seja, salvar a vida de um ou de outro são ações igualmente importantes. Uma das objeções levantadas é a de que, se dois atos são moralmente equivalentes, então ambos são permitidos e nenhum deles seria absolutamente obrigatório (CONEE, 1982, p. 96). Portanto, esse dilema moral não seria genuíno, pois seria indiferente optar por um gêmeo ou outro, já que os dois cursos de ação seriam permitidos e não seriam absolutamente obrigatórios. Este talvez seja um modo questionável de negar os dilemas morais. Não parece que, se temos duas obrigações moralmente equivalentes, então elas sejam ambas permitidas. Tomemos como exemplo o seguinte caso: na Constituição Brasileira temos que o direito à vida e o direito de recusa por convicções religiosas são moralmente obrigatórios, mas existem inúmeros casos onde esses dois direitos se chocam, dando início a um dilema moral (FRANÇA et al, 2008, p. 501). Por serem moralmente equivalentes, não se segue que seja permitido fazer uma transfusão de sangue ferindo o direito à recusa por convicções religiosas ou que seja permitido deixar que alguém perca sua vida na sala do hospital.

Outro argumento para a defesa da existência de dilemas morais é estabelecido sobre o chamado resíduo moral, um efeito das situações conflitantes. A evidência de que existem dilemas morais é o sentimento de culpa que o agente sofre depois de realizar certa escolha em detrimento de outra. Esse sentimento é o resíduo moral que surge depois de uma escolha sobre as ações possíveis (WILLIAMS, 1965, p. 103-138). Uma formalização indutiva do argumento de Williams é a seguinte (MERLUSSI, 2013, p. 210):

1. Se um agente $S$ está diante de um dilema moral, então se arrepende adequadamente.

2. $S$ se arrepende adequadamente.

3. Portanto, $S$ está diante de um dilema moral. 
Por ser um argumento indutivo e a primeira premissa denotar uma implicação causal, e não material, ele pode ser aceito como válido (MERLUSSI, 2013, p. 210). Essas razões são dadas para não aceitarmos a primeira premissa e reformulá-la, e ainda poderíamos contestar contestaria a segunda premissa (CONEE, 1982, p. 92). Um erro apontado nesse argumento é dizer que o agente está diante de um dilema moral, já que na verdade ele somente crê estar diante de um dilema moral (MERLUSSI, 2013, p. 211). O seu arrependimento fica justificado somente pela sua crença de estar em uma situação dilemática, e não pela correspondência aos fatos. Portanto, o sentimento de culpa seria acarretado pela crença do agente aos fatos, e não da correspondência adequada da crença aos fatos.

Conee aponta que o arrependimento do agente $\mathrm{S}$ não seria necessariamente adequado aos fatos. Antes de tudo, o sentimento de arrependimento (ou culpa) é adequado à situação, mas apenas de modo subjetivo. Em outras palavras, o sentimento de culpa é acarretado pelos princípios morais que o agente $\mathrm{S}$ adota em relação à situação. $\mathrm{O}$ exemplo dele é suficiente para ilustrar tal posição: "se as suas convicções incluem que todas as dívidas devem ser pagas moralmente, é [adequadamente] apropriado à sua moralidade sentir culpa sobre ser inadimplente." (CONEE, 1962, p. 91-92, tradução nossa).

Nessa seção remontamos alguns argumentos bem conhecidos na literatura a favor dos dilemas morais: os dilemas morais como conflitos de diferentes naturezas, como fonte de um resíduo moral e como duas ações conflitantes moralmente equivalentes.

Para aqueles que defendem a existência dos dilemas morais como resultados de diferentes tipos de obrigação, a formalização dos dilemas poderia ser feita com uma lógica de obrigações hierarquizada, onde as obrigações morais e obrigações jurídicas, por exemplo, poderiam se diferenciar. Os que defendem, contudo, a existência dos dilemas morais como duas obrigações moralmente equivalentes devem lidar com o problema da trivialização do sistema de lógica deôntica padrão. Posições contrárias aos dilemas morais podem defender a lógica deôntica padrão, ainda que a formalização dos dilemas acarrete em uma contradição. Felizmente, tal contradição, diriam os contrários aos dilemas, é um sinal de que os dilemas morais são erros presentes em nosso discurso normativo natural. Acreditamos, portanto, que a maneira de considerar como os dilemas morais surgem afeta substancialmente o modo de formalização deles.

Partiremos para a breve análise da formalização dos dilemas morais tomando como base essas três posições relativas aos dilemas morais apresentadas. 


\subsection{A formalização de dilemas morais na lógica deôntica}

Outra questão que participa da discussão sobre os dilemas morais e a lógica deôntica é: de que modo devemos formalizá-los? Na seção anterior, definimos informalmente o que seria uma situação dilemática. Para darmos um passo mais próximo à lógica deôntica, delimitaremos o que é um dilema moral.

Definição 2. Dilema moral:

(a) Dada uma situação ética $\mathrm{S}$ qualquer, ela será um dilema moral se e somente se há um agente $\mathrm{A}$ em $\mathrm{S}$ que é moralmente obrigado a seguir um curso de ação $\mathrm{A}$ e moralmente obrigado a seguir um curso de ação B, mas não pode seguir ambos os cursos de ação.

Essa definição aparece em outros trabalhos, seguida de um argumento de que os dilemas morais são fenômenos do discurso e por isso precisam ser representados na lógica deôntica (AMARAL, 2012, p. 44). Se a lógica deôntica trata do discurso normativo, então ela deveria ser capaz de formalizar e analisar os dilemas morais apropriadamente.

Apresentamos três dilemas morais e resta-nos analisar como eles podem ser formalizados na lógica deôntica clássica, já apresentada aqui, tomando como definição de dilema moral o que foi dito acima. Além disso, falaremos sobre quais são as consequências de tais formalizações, como propõe um dos objetivos deste artigo.

De início, podemos tomar o dilema de Platão e formalizá-lo na lógica deôntica padrão (TESTA, 2008, p. 30):

1. É obrigatório cumprir a promessa [Op]

2. É proibido contribuir com o assassinato [O c]

3. Cumprir a promessa me obriga a devolver a arma $[\mathrm{O}(\mathrm{p} \rightarrow \mathrm{a})]$

4. Não contribuir com o assassinato me proíbe devolver a arma $[\mathrm{O}(\sim \mathrm{c} \rightarrow \sim \mathrm{a})]$

Com alguns $\operatorname{passos}^{8}$, pode-se deduzir (Oa \& O a) e com a conjunção dessa fórmula com o teorema (DM) temos uma contradição. É importante distinguirmos nesse sentido que o problema, nesse caso, é inerente ao sistema de lógica deôntica clássica e não aos dilemas morais. O modo que formalizamos o dilema de Platão na lógica encaixa-se, aparentemente, com a definição de dilemas morais dada aqui. O motivo é claro: parece existir uma diferença no sentido de 'obrigação do cumprimento de uma promessa' e de uma 'obrigação de não

8 A partir da instância do axioma (D3) na forma ' $\mathrm{O}(\mathrm{p} \rightarrow \mathrm{a}) \rightarrow(\mathrm{Op} \rightarrow \mathrm{Oa})$ ', com a linha 3 podemos utilizar (RD1) e chegar na fórmula '(Op $\rightarrow \mathrm{Oa})$ ' que, por sua vez, com a linha 1 e (RD1), fornece-nos Oa. Analogamente, os passos podem ser feitos utilizando (D3) e instanciando ' $\mathrm{O}(\sim \mathrm{c} \rightarrow \sim \mathrm{a}) \rightarrow(\mathrm{O} \sim \mathrm{c} \rightarrow \mathrm{O} \sim \mathrm{a})$ ', chegando a ' $\mathrm{O} \sim \mathrm{a}$ '. 
contribuir para um assassinato'. Tomando a interpretação de Lemmon e a diferença da natureza das obrigações, poderíamos considerar tal formalização equivocada já que considera as possíveis ações envolvidas na situação como de mesmo nível de obrigatoriedade, o que não é o caso.

Para ilustrar melhor: quando dizemos que somos obrigados a manter uma promessa e obrigados a salvar uma vida em perigo, estamos falando de deveres de "níveis diferentes". Não faria sentido utilizar um só operador deôntico de obrigação para ambas as ações, já que elas não seriam obrigações moralmente equivalentes. Portanto, a formalização desse tipo de dilema moral utilizando somente um operador de obrigação seria um equívoco, pois colocaria dois tipos de obrigações diferentes em níveis iguais. O operador de obrigação da lógica deôntica padrão sozinho não consegue captar a diferença entre um dever que surge de um princípio moral e uma obrigação, usando a distinção de E. J. Lemmon. Assim, essa contradição lógica seria apenas aparente e fruto de um erro de tradução da noção de "obrigação" da linguagem natural para a linguagem formal. O mesmo ocorre com o dilema de Sartre. Ambas as formalizações acarretariam em contradições. ${ }^{9}$ Os indícios, portanto, são dois: ou a pressuposição dos dilemas morais está correta e o problema está no sistema lógico, ou não deveria haver tal diferenciação de obrigações, salvando assim o sistema clássico deôntico.

Aqueles que aceitam a interpretação de Ruth Marcus de que duas obrigações equivalentes acarretaria um dilema moral, aceitariam tal formalização sem problemas. A obrigação de cumprir uma promessa e de não contribuir com um assassinato seriam de mesmo valor, ou seja, seriam moralmente equivalentes. Esses deveriam lidar com a contradição obtida pela formalização dos dilemas morais. A solução para os que precisam lidar com a inconsistência da formalização dos dilemas morais é a criação de outro sistema lógico deôntica, acrescentando novos operadores que fortaleçam a linguagem.

Uma das alternativas para solucionar tal questão é a adição de operadores de obrigação que se diferenciam como, por exemplo, um operador de obrigações judiciais e outro para obrigações morais. Nesse sentido, o dilema de Platão não acarretaria em uma contradição, pois a obrigação de não contribuir para um assassinato estaria ligada a uma obrigação judicial (e, de certa maneira, moral), ao passo que cumprir uma promessa está mais ligada a uma obrigação moral do que judicial em um sentido estrito. Diferenciar uma obrigação judicial e

9 Uma contradição na lógica clássica torna o conjunto de fórmulas inconsistente e o torna trivial, fazendo com que ele deduza qualquer fórmula do sistema. Em particular, no caso da lógica deôntica clássica, a contradição poderia acarretar em infinitas obrigações e permissões. 
moral e postular certa hierarquia, favorece a dissolução do dilema moral proposto e é semelhante à proposta de E. J. Lemmon. Para essa solução, é possível apresentar um sistema de lógica deôntica que toma operadores de moralmente obrigatório e judicialmente obrigatório como primitivos (SERBENA; CELLA, 2010, p. 6-10).

Até o momento, lidamos com os dilemas apresentados por E.J. Lemmon. Entretanto, o dilema moral dos gêmeos em perigo parece ser um caso especial a ser tratado. Neste caso, intuitivamente consideramos que a obrigação de salvar um gêmeo A é a mesma que salvar o gêmeo B. A formalização seria semelhante, mas as obrigações são de mesmo nível:

1. É obrigatório salvar o gêmeo A [Oa]

2. É obrigatório salvar o gêmeo $\mathrm{B}[\mathrm{Ob}]$

3. É obrigatório que, salvar o gêmeo A, acarreta em não salvar o gêmeo B $[\mathrm{O}(\mathrm{a} \rightarrow \sim \mathrm{b})]$

4. É obrigatório que, salvar o gêmeo A, acarreta em não salvar o gêmeo B $[\mathrm{O}(\mathrm{b} \rightarrow \sim \mathrm{a})]$

Ainda surge uma contradição, mas parece que há um equívoco cometido nessa formalização: a interpretação da obrigação dos condicionais. Se as premissas 3 e 4 usassem o operador modal de "necessidade", pois o operador de obrigação é análogo a esse, essa implicação seria mais bem traduzida. A quarta premissa pode ser lida como "É necessário que salvar o gêmeo A implica em não salvar o gêmeo B”. Nesse caso, temos problemas novamente com a capacidade de expressão lógica na linguagem formal da lógica deôntica clássica.

Prosseguindo com as análises, resta-nos citar mais um exemplo de dilema moral já comentado neste trabalho: o conflito entre o direito à vida e o direito à escolha religiosa. Suponha uma situação Z, onde um médico M é obrigado a realizar uma transfusão de sangue em um paciente $\mathrm{P}$ (curso de ação que chamaremos de $\mathrm{T}$ ), mas ao mesmo tempo, precisa respeitar a convicção religiosa desse paciente que o impede de realizar essa transfusão de sangue (curso de ação que chamaremos de R). Em outras palavras:

1. É obrigatório que se eu realizar a transfusão de sangue no paciente $P$, então respeitarei o direito à vida $[\mathrm{O}(\mathrm{t} \rightarrow \mathrm{v})]$

2. É obrigatório respeitar a escolha desse paciente [Or]

3. Respeitar a escolha do paciente implica em não respeitar o direito à vida. $[\mathrm{O}(\mathrm{r} \rightarrow \sim \mathrm{v})]$

4. É obrigatório realizar a transfusão de sangue [Ot] 
Nesse caso, outra contradição ocorreria do seguinte modo:

\begin{tabular}{ll|l} 
1. & $\mathrm{O}(\mathrm{t} \rightarrow \mathrm{v})$ & $\mathrm{P}$ \\
2. & $\mathrm{O}(\mathrm{r} \rightarrow \mathrm{v})$ & $\mathrm{P}$ \\
3. & $\mathrm{Or}$ & $\mathrm{P}$ \\
4. & $\mathrm{Ot}$ & $(\mathrm{D} 3)$ \\
5. & $\mathrm{O}(\mathrm{t} \rightarrow \mathrm{v}) \rightarrow(\mathrm{Ot} \rightarrow \mathrm{Ov})$ & $(\mathrm{D} 3)$ \\
6. & $\mathrm{O}(\mathrm{r} \rightarrow \sim \mathrm{v}) \rightarrow(\mathrm{Or} \rightarrow \sim \mathrm{Ov})$ & $1,5(\mathrm{RD} 1)$ \\
7. & $\mathrm{Ot} \rightarrow \mathrm{Ov}$ & $2,6(\mathrm{RD} 1)$ \\
8. & $\mathrm{Or} \rightarrow \mathrm{O} \sim \mathrm{v}$ & $4,7(\mathrm{RD} 1)$ \\
9. & $\mathrm{Ov}$ & $3,8(\mathrm{RD} 1)$ \\
10. & $\left.\mathrm{O} \sim \mathrm{v} \rightarrow(\mathrm{I}-\mathrm{C})^{10}\right)$ \\
11. & $\mathrm{Ov} \rightarrow(\mathrm{O} \sim \mathrm{v} \rightarrow(\mathrm{Ov} \& \mathrm{O} \sim \mathrm{v})$ & $9,11(\mathrm{RD} 1)$ \\
12. & $\mathrm{O} \sim \mathrm{v} \rightarrow(\mathrm{Ov} \& \mathrm{O} \sim \mathrm{v})$ & $10,12(\mathrm{RD} 1)$ \\
13. & $\mathrm{Ov} \& \mathrm{O} \sim \mathrm{v}$ & $(\mathrm{DM})$ \\
14. & $\sim(\mathrm{Ov} \& \mathrm{O} \sim \mathrm{v})$ & $(\mathrm{I}-\mathrm{C})$ \\
15. & $(\mathrm{Ov} \& \mathrm{O} \sim \mathrm{v}) \& \sim(\mathrm{Ov} \& \mathrm{O} \sim \mathrm{v})$
\end{tabular}

Os princípios bioéticos, por exemplo, são os que mais sofrem com esse tipo de dilema moral. Respeitar a autonomia do indivíduo ou a Constituição seria um dilema entre um dever como médico e um dever como cidadão se adotássemos como verdadeira a posição de Lemmon.

\section{CONSIDERAÇÕES FINAIS}

Mostramos que aceitar a existência dos dilemas morais e assumir a lógica deôntica clássica faz a formalização dos dilemas morais acarretar em uma contradição. Três alternativas para fugir da trivialização do sistema deôntico são as seguintes: (i) negação do princípio de explosão, (ii) exclusão do axioma (C) (Op \& Oq) $\rightarrow \mathrm{O}(\mathrm{p} \&$ q) (também conhecido como princípio de aglomeração) ou (iii) remoção da regra (RM) que impõe que se $(\mathrm{p} \rightarrow \mathrm{q})$ é um teorema, então $(\mathrm{Op} \rightarrow \mathrm{Oq})$ também é um teorema (GOBLE, 2005, p. 465-468).

10 Sejam $p$ e $q$ proposições. Este é o axioma da introdução de conjunção na lógica deôntica clássica: $(\mathrm{p} \rightarrow(\mathrm{q} \rightarrow(\mathrm{p} \& \mathrm{q})))$. Ela diz que se temos $p$ e $q$ atômicas, então podemos deduzir (p \& q) com o uso da regra (RD1). Chamaremos de I-C (introdução da conjunção) a instância desse axioma. 
Os defensores dos dilemas morais precisam resolver o problema da formalização e propor ao menos uma alternativa para evitar a contradição. No sistema bimodal, a proposta de formalização de dilema moral é a seguinte: (Op \& Oq) \& ৩(p \& q) (AMARAL, 2012, p. 48). Lê-se do seguinte modo: "É obrigatório que se faça $p$ e é obrigatório que se faça $q$, e não é possível $^{11}$ fazer $p$ e $q$ ". Consideremos $p$ como 'devolver a arma' e $q$ como 'evitar um assassinato'. Lê-se, a partir dessas interpretações, “É obrigatório devolver a arma e é obrigatório evitar um assassinato, e não é possível fazer devolver a arma e evitar um assassinato". A solução proposta é a de recusar o princípio de aglomeração e aceitar a regra de O-necessitação (RM). Assim como o dilema de Platão, outros exemplos de dilemas também podem ser formalizados nesses moldes.

Outra alternativa é formalizar os dilemas morais no cálculo deôntico paraconsistente monádico (DA COSTA; CARNIELLI, 1976, P. 295). Por ser paraconsistente (a lei da explosão não é válida nesse sistema), o problema da trivialidade já não ocorre.

É possível, ainda assim, achar uma nova alternativa sobre os dilemas morais: negar sua existência e sustentar que tentar formalizá-los seria incorrer em um erro. Se os dilemas morais não existem, então não faz sentido que eles sejam analisados pela lógica, mesmo que façam parte da nossa linguagem natural. Defender a lógica deôntica clássica e aceitar o princípio de explosão não seria um problema nesse caso, desde que os dilemas morais genuínos fossem recusados.

Conclui-se a partir do que foi exposto neste trabalho que ainda há muito que explorar nas lógicas deônticas e na discussão sobre os dilemas morais. Por isso estamos longe de resolver boa parte dos problemas que aparecem aos pesquisadores que estão na intersecção da Lógica e da Ética. Além disso, expomos que as posições favoráveis ou contrárias aos dilemas morais interferem diretamente em suas formalizações em um sistema lógico. Em outras palavras, aceitar ou não a formalização dos dilemas morais é uma escolha cuja justificativa precede a postulação de um sistema lógico para lidar com os dilemas morais. Por fim, sugerese que trabalhos futuros analisem como a lógica deôntica pode ser expandida para tratar de situações jurídicas e bioéticas, como propõe lógica de normas e casos (TESTA, 2008, p. 33). Ademais, concordamos que a lógica de hierarquias institucionais, que diferencia obrigações entre instituições, como a família e o Estado, possa ser uma alternativa (CASTAÑEDA, 1975, p. 263).

$11 \mathrm{O}$ símbolo ' $\diamond$ ' denota formalmente a noção de possibilidade ('é possível que $x$ ', ' $x$ é possivel'). Se $p$ significa 'Chove em Araranguá', então $\diamond$ p significa 'É possível que chova em Araranguá'. 


\section{REFERÊNCIAS}

AMARAL, Juliana de Paula Ferraz do. Representação de dilemas morais em lógica deôntica. Florianópolis. 89. Dissertação em Filosofia. Universidade Federal de Santa Catarina. 2012.

CASTAÑEDA, Hector-Neri. Thinking and Doing: The Philosophical Foundations of Institutions. Dordrecht: D. Reidel Publishing Company, 1975.

CONEE, Earl. Against moral dilemmas. The Philosophical Review, v. 91, n. 1, p. 8797, 1982.

CRUZ, A. M. P. Lógica deôntica paraconsistente: paradoxos e dilemas. Natal: Editora da UFRN, Brazil, 2005.

DA COSTA, Newton CA; CARNIELLI, Walter A. On paraconsistent deontic logic. Philosophia, v. 16, n. 3-4, p. 293-305, 1986.

FOOT, Philippa (1967). The problem of abortion and the doctrine of double effect. Oxford Review, 5, 5-15.

FRANÇA, Inacia Sátiro Xavier de; BAPTISTA, Rosilene Santos; BRITO, Virgínia Rosana de Sousa. Ethical dilemmas in blood transfusion in Jehovah's Witnesses: a legalbioethical analysis. Acta Paulista de Enfermagem, v. 21, n. 3, p. 498-503, 2008.

GOBLE, Lou. A logic for deontic dilemmas. Journal of Applied Logic, v. 3, n. 3-4, p. 461-483, 2005.

HILPINEN, Risto. Deontic Logic: Introductory and Systematic Readings. Holanda: D. Reidel, 1981.

LEMMON, Edward John. Moral dilemmas. The philosophical review, v. 71, n. 2, p. 139-158, 1962.

LOKHORST, Gert-Jan C. et al. Ernst Mally's Deontik (1926). Notre Dame Journal of Formal Logic, v. 40, n. 2, p. 273-282, 1999.

MARCUS, Ruth Barcan. Moral dilemmas and consistency. The Journal of Philosophy, v. 77, n. 3, p. 121-136, 1980.

MERLUSSI, Pedro. Há dilemas morais?.ethic@ - An international Journal for Moral Philosophy, v. 12, n. 2, p. 207-226, 2013.

SERBENA, Cesar Antonio; CELLA, José Renato Gaziero. Lógica deôntica paraconsistente e hard cases. 2010. 
SILVA, Ricardo Tavares da. Paradoxos da lógica deôntica: Indícios de um equívoco. Kriterion: Revista de Filosofia, v. 58, n. 138, p. 673-690, 2017.

TESTA, Rafael Rodrigues. Dilemas deônticos: Uma abordagem baseada em relações de preferência. Campinas. 75. Dissertação em Filosofia. Universidade Estadual de Campinas. 2008.

VON WRIGHT, Georg Henrik. Deontic logic. Mind, v. 60, n. 237, p. 1-15, 1951.

WILLIAMS, Bernard AO; ATKINSON, W. F. Symposium: Ethical Consistency. Proceedings of the Aristotelian Society, Supplementary Volumes, p. 103-138, 1965. 


\section{AGRADECIMENTOS}

Aos meus pais, Renato Santana e Andrea Bitencourt, pelo amor e apoio incondicionais.

Ao Conselho Nacional de Desenvolvimento Científico e Tecnológico - CNPq e à Universidade Federal de Santa Catarina pela oportunidade de desenvolver essa pequena pesquisa voluntária na área de Lógica e Ética.

Ao Prof. Dr. Darlei Dall'Agnol pelos incentivos, ensinamentos e escolha de me orientar no projeto de pesquisa voluntária que acarretou a produção deste trabalho.

Aos amigos André Barbosa e Jucemar Paes pela amizade e pelas conversas que me auxiliaram durante minha pesquisa e produção deste trabalho. 